\title{
EFFECT OF \\ THE TESTIS ON OVARIAN DIFFERENTIATION \\ IN HETEROSEXUAL EMBRYONIC RAT \\ GONAD TRANSPLANTS ${ }^{1}$
}

\author{
M. NEIL MACINTYRE ? \\ Department of Zoology, University of Michigan, Ann Arbor \\ TWELVE FIGURES \\ INTRODUCTION
}

Early in its embryology the vertebrate gonad, generally speaking, exists for a time as an undifferentiated but bipotential anlage consisting of a cortical component with female potentialities and a medullary component with male potentialities. In a genetic female the cortex persists and develops at the expense of the medulla to become an ovary, whereas in genetic male the converse is true (Willier, '39).

The physiological basis for sex differentiation in vertebrates has received considerable attention from numerous investigators since the "freemartin" phenomenon was first described by Lillie ('16, '17) and by Keller and Tandler ('16). The now voluminous literature dealing with sex determination and differentiation in representatives of all vertebrate classes attests to the fact that interest in this problem has been productive. Reference to the significant work in this field will be found in certain recent papers (Burns, '49, '50; Jost, '50; Moore, '47, '50; Wells, '50).

${ }^{1}$ Based on a dissertation entitled "Cortico-medullary induction of sex differentiation in the albino rat," submitted in partial fulfillment of the requirements for the degree of Doctor of Philosophy in the University of Michigan, 1954.

${ }^{2}$ Present address: Department of Anatomy, School of Medicine, Western Reserve University, Cleveland 6, Ohio. 
Some of the most important experimentation was done at the amphibian level and the knowledge gained from this work led Witschi ('34) to the following conclusions which form a portion of his theory concerning the so-called "cortico-medullary inductors" of sex differentiation in amphibia:

1. Female and male determining genes independently cause the appearance of gonadal cortical and medullary inductors separately.

2. The inductors produce their effects by the release of morphogenic substances called "medullarin" and "cortexin."

3. In addition to stimulative induction, both cortex and medulla exhibit inhibitive functions by which each may be the antagonist of the other.

4. In the genetic male the cortex is "weaker" than the medulla and becomes suppressed, whereas the converse is true in genetic females.

Subsequent experimentation with amphibians by Witschi and others has continued to support Witschi's theory, but work with higher vertebrates has not proven so fruitful and has, at the mammalian level, generally failed to produce significant gonadal changes.

Most of the investigators using mammals have employed techniques which involve the administration of sex hormones. Results of such experimentation are in accord from a qualitative standpoint and from them it may be concluded that treatment of mammalian embryos with sex hormones generally leads to changes in the secondary sex characters including the duct systems and external genitalia. However, reports of changes in the primary sex characters, the gonads, under the influence of hormone administration are significantly searce.

After reviewing the work done in this field it seemed evident that an adequate method of investigating normal sex differentiation mechanisms at the mammalian level had yet to be devised. If the theory of cortico-medullary induction proposed by Witschi to explain sex differentiation in amphibians is valid for mammals, it seemed entirely possible that the embryonic inductors "cortexin" and "medullarin", 
might be effective only over short distances as seems to be the case in some of the amphibian forms (Witschi, '34). A developmental mechanism of this sort would be adequate to cause the initial development of an undifferentiated mammalian gonad into a testis or ovary since the male and female primordia (medulla and cortex) are in direct mutual contact.

With these thoughts in mind it was decided, as the central technique of this work, to grow embryonic rat gonads together in heterosexual pairs in an environment devoid of adult sex hormones. This would, in effect, be placing tissue in which differentiation is chiefly cortical next to tissue in which differentiation is chiefly medullary, thereby closely approximating the anatomical situation found in a single normal mammalian gonad at the indifferent stage in its development.

That phase of the investigation described in this paper involved approximately 100 tissue transplantations.

Grateful acknowledgment is made to Professors Paul A. Wright and Norman E. Kemp of the Department of Zoology, University of Michigan, for their guidance, encouragement, and assistance in this research.

\section{MATERIALS AND METHODS}

In a 15-day old rat embryo the testis may be distinguished from the more slowly-developing ovary. The gonads of both sexes at this stage may be surgically separated from adjacent structures and removed. Transplantations of such gonads were made to a subcapsular position in the kidneys of adult rat hosts which had been castrated at least three weeks prior to their use. This 21-day period is considered as being more than adequate to assure the elimination of gonadal sex hormone from the host's blood (Dingemanse and Laqueur, '37; Moore et al., '30).

Results of a trial series of transplants in which the embryonic tissue was left in the host site for periods varying from one to four weeks, indicated that by the end of three 
weeks the transplanted tissues had attained a considerable degree of growth and differentiation without showing the tendency toward degeneration exhibited by some of the month old grafts. Consequently, the period of three weeks in the kidney site was established as standard. Vascularization of the explants was extensive, and examination of sectioned tissues after various periods of growth as transplants indicated that their blood supply had been comparable to that of normal gonads of the same age.

Both growth and differentiation of transplanted single gonads, used as controls, was in most cases actually in excess of that found in normal gonads. This hyperplasia was possibly due to an abnormally high level of pituitary gonadotrophic hormone in the blood of the host as a result of castration. (Engle, '29; Evans and Simpson, '29; Kallas, '30).

In early experiments both male and female castrate hosts were used in equal numbers, but it soon became apparent that the sex of the host was not a significant factor since all noteworthy results were obtained from hosts of both sexes. Males were then used almostly exclusively as hosts since their castration could be accomplished with considerably greater facility.

After removal from the host, explants were fixed in Bouin's fluid, imbedded in paraffin, sectioned serially at $8 \mu$, and stained with Heidenhain's azan modification of Mallory's triple stain.

\section{RESULTS}

\section{Transplanted testis and ovary}

Since the main goal of this experinent was to determine the possible effects of gonadal tissue of one sexual potentiality upon that of the opposite potentiality early in development, the basic experimental pattern was to transplant a 15-day embryonic testis next to a 15-day embryonic ovary. One gonad of each sex was transplanted to each host kidney in such a position that the explants were located side by side and in mutual contact. Thus, any secretions from either 
gonad could diffuse directly into the other gonad with the least possible difficulty.

In view of the fact that the testis begins its differentiation earlier than does the ovary in the rat, it was anticipated that if one of the transplanted gonads proved capable of inhibiting the development of the other, the testis should be the inhibiting tissue and the ovarian transplant should show the effects of such inhibition. Analysis of the experimental results showed not only inhibition of the ovary by the testis in every case but even a partial transformation of ovarian tissue into testis-like structures in several instances.

Five of the grafts were removed after two weeks in the host and 21 transplants were allowed to remain for a period of three weeks before removal. The effects shown by the two-week grafts were so similar to those evident in the older tissues that the two groups will be considered here as one. Three of the 26 transplants were unsuceessful grafts and failed to prosper in the host site. In all of the remaining 23 transplants the testicular portion exhibited normal or better than normal growth and differentiation while none of the ovaries developed normally.

The ovarian portions of 9 transplants were almost completely inhibited (fig. 3), with but a few isolated groups of sex cords and an occasional primary follicle ${ }^{3}$ in evidence. The remaining grafts showed in addition to marked ovarian inhibition, the formation of tubular structures within the ovarian tissue. These tubules, although usually not so symmetrical as the seminiferous tubules of the testis, were of similar construction (figs. 4, 6, 8).

Of the grafts in which these tubular structures developed, 7 were devoid of normal follicles, containing only empty or

${ }^{3}$ Terminology used throughout this discussion:

Primary follicle: One with a single layer of follicular cells.

Secondary follicle: One with more than one layer of follieular cells but without antra.

Vesicular follicle: One containing an antrum or antra.

Graafian follicle: One with a large antrum and well developed cumulus oophorus. 
degenerate primary follicles. Six of the transplants had developed, in addition to the tubules, a few normal appearing primary and secondary follicles containing oocytes. These follicles were scattered among the tubular structures and in several cases the follicular thecae instead of exhibiting the characteristic circular shape in section, were distorted and elongated (fig. 7), a condition which appeared to be intermediate between normal follicles and the ovarian tubules. The most interesting and significant result was obtained in one transplant in which numerous well developed oocytes were found within the lumen of the tubules (figs. 8 and 9). Several of the tubules in this case were large and irregular in outline, whereas others appeared to be practically identical in shape with normal seminiferous tubules. Careful analysis showed that these oocyte-bearing tubules were not confined to a small portion of the ovarian tissue but were present in nearly every serial section.

The presence of oocytes within the tubular ovarian structures is considered as an indication that the tubules developed from ovarian sex cords which, instead of forming normal follicles, retained their elongated form and developed lumina under the influence of the adjacent testicular tissue. Also in support of this concept is the fact that the multiple layers of reticulo-collagenous connective tissue surrounding the tubular structures (fig. 6) are suggestive of follicular thecae and are not characteristic of testicular tissue. The possibility that true seminiferous tubules had migrated from testicular to ovarian tissue in the transplant, was discounted after careful tracing through serial sections failed to disclose any instance of a tubule crossing the connective tissue barrier between testis and ovary. Even if evidence of such migration had been found it would be difficult to explain how the vagrant seminiferous tubules came to contain oocytes.

\section{Controls}

Transplanted testis without ovary. The basic method of controlling the experimental procedure involved the trans- 
plantation of individual gonads to determine how well an embryonic testis or ovary would develop in the subcapsular kidney site of the host in the absence of gonadal tissue of the opposite sex. The necessity of such control was not so great in the case of the testes as it was for the ovarian transplants since previous experiments had already shown that the testis was capable of developing well in the presence of ovarian tissue of the same age. There was little reason to feel that it would exhibit less capacity when grown in transplant by itself. Nevertheless, 6 transplants of 15-day embryonic testes were made in adult castrate hosts to serve both as a comparison with normal testes and with those grown in the presence of ovaries.

Two of the transplants were removed after the first week, two after the second week, and the last two at the end of three weeks. At each age the transplants greatly resembled the testicular portions of the double grafts involving 15-day gonads of both sexes, and at each age the tissue showed some precocity of growth and differentiation as compared with normal testes of equivalent age. The fact that the testicular tissues of the double transplants showed a similar advance in developmental rate over that of normal testes has been mentioned previously.

Transplanted ovary without testis. Quite obviously there was a definite need for controlling the experimental procedure with respect to the ovarian tissue. If it could be shown at a 15-day embryonic ovary transplanted to a castrate adult host would develop well in the absence of testicular tissue when ovarian transplants grown in conjunction with testes had been inhibited, this would indicate the probable existence of some substance elaborated by the testis and capable of affecting the development of the ovary. If, on the other hand, normal ovarian development proved to be equally inhibited merely by the transplantation technique and/or the transplantation environment, there would then be no basis for a claim that the testis was capable of influencing ovarian development. To establish this basic point, 10 transplants of single 15-day 
embryonic ovaries were made and allowed to grow for various periods of time. One such transplant was removed after one week, three were taken after two weeks, 4 were grown for three weeks, and two remained in the host for 4 weeks.

The ovary removed from transplantation after only one week contained many sex cords and in addition, several healthy primary follicles which are not present in a normal ovary of equivalent age, i.e., newborn. All three of the ovaries taken from the host after two weeks showed some remaining sex cords and contained many primary follicles and even a few secondary follicles. Of the 4 ovarian transplants removed after three weeks, one was very degenerate and was considered to be an unsuccessful graft. Tissues of the other three were in excellent condition, containing many primary and secondary follicles and, in the case of one ovary, even a few follicles in the early vesicular stage (fig. 11). Both of the month old transplants were in excellent condition and showed many follicles up to and including an early Graafian level.

These results left no doubt concerning the ability of transplanted ovaries to develop well when not under the influence of adjacent testicular tissue, and highlighted the probability that the ovarian inhibition and/or transformation encountered in the previously described experiments was due to a secretion from the testicular tissue involved.

Transplanted ovary with non-gonadal tissue. Although it was clear that the ovarian grafts thrived in the absence of a testis and were seriously inhibited and/or transformed toward the male direction when grown next to testicular tissue of the same age, there remained the slight possibility that the ovarian abnormalities resulting from growing next to a testis might result from the proximity of any other tissue, not necessarily testicular tissue. It seemed quite improbable that this concept would be valid bccause the control ovaries had developed well next to the foreign tissue of the host kidney. Nevertheless, a short series of transplants was made with 15-day embryonic ovaries next to non-gonadal tissue 
taken from littermate donors. All of these grafts were left for three weeks in the host animal.

Adrenal tissue was the first of a non-gonadal nature to be selected because it would not only represent a foreign tissue but would also test the possibility of ovarian inhibition resulting from adrenocortical androgens. In one case one half of an adrenal gland was placed next to the ovary while in a second graft a whole adrenal gland was used. In both cases the ovary developed as well as if no foreign tissue were present (fig. 10), in fact, several of the resulting ovarian follicles were larger than those encountered in the three week control ovaries (fig. 2) indicating the possibility of a facilitating effect on ovarian development by the adrenal. The adrenal tissue itself developed very well and in each case exhibited an easily recognizable cortex and medulla, the histology of which appeared entirely normal.

Two transplants were made with portions of spleen as the non-gonadal component with no resulting ill effects upon ovarian development. The splenic tissue was not organized into definite red and white pulp areas as in the adult gland, but evidence of its normal hemopoietic activity was given by blood cells of several types and in several stages of development, located in vesicular areas within the splenic tissue.

A portion of small intestine was used as a third type of non-gonadal transplant companion for ovarian tissue and again the ovary developed as well as did the ovarian controls, with numerous primary and secondary follicles being in evidence. The intestinal tissue had grown extensively, making the transplant exceptionally large at the time of removal. Many of the epithelial cells had sloughed from the intestinal mucosa into the lumen of the intestinal segment indicating a possible autolytic enzymatic action.

Although this investigation involving non-gonadal tissue was by no means exhaustive, its results were interpreted as a clear indication that non-testicular tissues have no demonstrable inhibitory effect on developing ovaries. 
Transplanted ovary in normal male host. In the hypothesis which inspired the research reported here, Witschi ('34) suggested that cortexin and medullarin produced by the developing vertebrate gonad are not identical with the hormones estrogen and testosterone elaborated by the adult sex glands. In all of the experiments reported above, the host animals were castrated in order to eliminate adult gonadal hormones from the experimental picture. If, however, the substance which Witschi calls medullarin is actually identical with the adult male hormone as several investigators have implied, it seemed logical that the inhibition of ovarian development ought to be reproducible in an environment containing the normal adult level of testosterone. To investigate this possibility a series of transplants was made in which 15-day embryonic ovaries were placed alone beneath the renal capsules of normal (non-castrate) adult male hosts and allowed to remain there for three weeks.

One of these transplants failed to "take" and the ovarian tissue was very degenerate when removed from the host, but in all of the 5 remaining cases the ovary had developed well, producing numerous healthy follicles of all stages up to and including a few of vesicular size despite the presence of testosterone in the circulation of the host (fig. 12). Histological examination of the serial sections of these tissues showed that vascularization was extensive and there was little doubt of the fact that the cells of the grafted ovaries had ample opportunity to be affected by the adult male hormone of the host. These negative results are in agreement with similar findings by Buyse ('35), Moore and Price ('42), and Holyoke ('49), all of whom concluded that developing rat gonads transplanted to normal adult hosts of the opposite sex are not appreciably influenced by the hormonal environment of the transplantation site.

\section{DISCUSSION}

This study was undertaken in an effort to investigate the "cortico-medullary inductor" theory proposed by Witschi ('34), in mammals. Since Witschi's work indicated that the 
embryonic gonadal inductors "cortexin" and "medullarin" may be effective only within a narrow range, the experimental technique used in this investigation involved the growth of embryonic gonadal cortical tissue in contact with tissue of medullary composition in a close approximation of the anatomical situation found in a single mammalian gonad during normal early development. Previous investigations of a similar nature have not been designed to place the male and female gonadal components in contact.

It is significant to note that in all of the experimental grafts involving both testis and ovary, the testicular tissue developed in typical fashion, but in none of these transplants did the ovary develop normally. It is possible, of course, that some of the ovaries would not have developed even in the absence of testicular tissue since Buyse ('35) and Holyoke ('49) have both reported less success with ovarian grafts than with those of testicular tissue. It should be noted, however, that in the control series 10 transplants were made with ovaries alone, and of those 10 only one failed to develop. This was a small series to be sure, but it indicates a far higher percentage of successful ovarian grafts than obtained by either Buyse or Holyoke. Perhaps the differences in the techniques involved are responsible for the disparity in results. When it is realized that $100 \%$ of the ovaries in heterosexual transplants exhibited inhibition and/or transformation whereas $90 \%$ of the control ovaries grown in the absence of a testis developed well, it must be concluded that the presence of a testis in some way affects ovarian growth and differentiation even assuming that a certain number of ovaries would have failed to grow under any circumstances.

The mere presence of seminiferous-like tubules in the ovarian portions of several heterosexual grafts is not in itself indicative of influence by the adjacent testicular tissue. Buyse, Moore and Price, and Holyoke all mentioned finding occasional examples of similar structures in ovarian grafts with no transplanted testis present. From the published data, however, it seems that none of these investigators has obtained 
the tubular anomalies in such quantity or in such a highly developed form as described in this work. One of the most significant questions concerns the origin of the ovarian tubules. Buyse, Moore and Price, and Holyoke refer to them as medullary elements within the ovary, but at least three points favor the classification of these tubules as "converted follicles" of cortical or secondary sex cord origin: (1) Some of the tubules have been found to contain well developed oocytes (figs. 8, 9) which would imply that the germ cells involved had developed under cortical influence. (2) Tubules were found intermingled with normal follicles and several follicles were observed which were apparently normal in every respect except that instead of being circular in section, they were distorted as if in the initial stages of tubule formation. (3) The accumulation of reticulo-collagenous tissue surrounding most of the tubules was highly suggestive of normal follicular thecae whereas no such cellular architecture is present about seminiferous tubules or medullary cords.

The possibility of ovarian inhibition resulting from the mere presence of foreign tissue in the transplantation site rather than from a secreted inhibitor of testicular origin, has been controlled by the experiments in which adrenal, splenic, and intestinal tissues were substituted for the testicular portion of the graft. In every such case the ovary developed well and to date there is no evidence of the inhibition of ovarian development by any tissue other than testicular.

The short series of ovarian grafts in normal, non-castrate hosts was made in order to confirm the previously cited work of Buyse, Moore and Price, and Holyoke. Results of their experiments as well as those reported in this paper indicate that ovaries transplanted to normal adult male hosts are not significantly altered in their development despite the presence of adult male hormone in the environment. It has been previously pointed out that such findings serve as evidence against the idea that embryonic gonadal inductors and adult sex hormones are one and the same substance. 
The investigation reported here indicates the probable existence of an inductor substance secreted by the medullary portion of a developing gonad. Research now in progress is aimed at demonstrating a similar secretion by the gonadal cortical anlage. Preliminary results have been encouraging.

SUMMARY

1. Embryonic gonads were taken from rat embryos of 15 days post coitum development and transplanted to a subcapsular position in the kidneys of castrated adult rats of both sexes. The bulk of the transplantations involved the combination of a testis and an ovary in each kidney. The grafts remained in the transplantation site for two or three weeks, the majority of them being removed at the end of the third week. Over $90 \%$ of all grafts were successful.

2. All successful transplants resulted in normal or slightly better than normal growth and differentiation of the testis, whereas all of the ovaries which were transplanted next to a testis were severely inhibited in development.

3. In addition to showing the effects of inhibition by the adjacent testis, several of the ovaries developed seminiferouslike tubules which in some cases contained well developed oocytes.

4. Control experiments in which 15-day embryonic ovaries were grown alone without the presence of testicular tissue resulted in normal ovarian development. Uninhibited ovarian growth was attained also in controls where embryonic adrenal, splenic, or intestinal tissue was grown next to the ovary.

5. Embryonic ovaries grown in normal, non-castrate adult male hosts developed normally despite the presence of adult male sex hormone.

6. These results are interpreted as substantiating at the mammalian level that portion of the cortico-medullary inductor theory of sex differentiation which deals with the secretion of an inductor by the medullary tissue of a developing gonadal anlage. Preliminary experiments indicate 


\section{the possibility of future support for the concept of a cortical inductor.}

\section{LITERATURE CITED}

Burns, R. K., JR. 1949 Survey of biological progress. Ed. by G. S. Avery, Jr., Academic Press, New York, 1: 233-266.

1950 Sex transformation in the opossum: some new results and a retrospect. Arch. d'anat. micr., 39: 467-483.

BUyse, A. 1935 The differentiation of transplanted mammalian gonad primordia. J. Exp. Zool., 70: 1-42.

DINGEMANSE, E., AND E. LAQUEUR 1937 On the inactivation of estrone, estradiol, and their monobenzoates in the organism. Am. J. Obst. and Gynee., 33: 1000-1009.

ENGLE, E. T. 1929 The effect of daily transplants of the anterior lobe from gonadectomized rats on immature test animals. Am. J. Physiol., 88: 101-106.

Evans, H. M., AND M. E. Simpson 1929 A comparison of anterior hypophyseal implants from normal and gonadectomized animals with reference to their capacity to stimulate the immature ovary. Am. J. Physiol., 89 : $371-374$.

Holyoke, E. A. 1949 The differentiation of embryonic gonads transplanted to the adult omentum in the albino rat. Anat. Rec., 103: 675-699.

Jost, A. 1950 Sur le contrôle hormonal de la différenciation sexuelle du lapin. Arch. d'anat. mier., 39 : 577-607.

KaLLAS, H. 1930 Zur Frage nach der Inneresekretorischen Tätigkeit des Infantilen Eierstockes, Klin. Wchnschr., $9: 1345-1346$.

Keller, K., AND J, TANDLER 1916 Ueber das Verhalten der Eihäute bei der Zwillingstrachtigkeit des Rindes. Untersuchungen ueber die Entstehungsursache der Geschlechtlichen Unterent-Wicklung von Weiblichen Zwillingskalbern, Welche Neben einem Männlichen Kalbe sur Entwickelung gelangen. Wien Tierartzl. Wehnschr., 3. Jahrg. s. $513-526$.

LiLuie, F. R. 1916 The theory of the free-martin. Science, 43: 611-613.

- 1917 The free-martin: a study of the action of sex hormones in the foetal life of eattle. J. Exp. Zool., 23: 371-452.

Moore, C. R. 1947 Embryonic sex hormones and sexual differentiation. (monograph) Charles C Thomas, Springfield, Ill.

1950 The role of the fetal endocrine glands in development. $J$. Clin. Endocrinol., 10: 942-985.

Moore, C, R., Wintfred Hughes and T. F. Galtagher 1930 Rat seminal vesicle cytology as a testis hormone indicator and the prevention of castration changes by testis extract injection. Am. J. Anat., 45: 109-135.

Moore, C. R., AND D. PRICE 1942 Differentiation of embryonic reproductive tissues of the rat after transplantation into postnatal hosts. J. Exp. Zool., 90: 229-265.

Wells, I. J. 1950 Hormones and sexual differentiation in placental mammals. Arch. d'anat. mier., 39: 499-517. 
Willier, B. H. 1939 Sex and Internal Secretions. Ed. by E. Allen, C. H. Danforth, and E. A. Doisy Williams and Wilkins Co., Baltimore. Chap. III, 64-144.

Witschi, E. 1934 Genes and inductors of sex differentiation in amphibians. Biol. Rev., $9: 460-488$. 


\section{PLATES}

\section{EXPIIANATION OF PLATES}

Al] grafts (figs. 3-12 incl.) were grown for three weeks as transplants before removal from the host kidney site. Castrated adult rat hosts were used for all transplants except that shown in figure 12.

\section{PLATE 1}

EXPLANA'IION OF FIGURES

1 Normal testis from 14-day old rat. This tissue and that shown in figure 2 are equivalent in age to the experimental tissues taken from 15-day embryos and grown for three weeks as transplants. $\times 91$.

2 Normal ovary from 14-day old rat. $\times 91$.

3 Graft of 15-day embryonic testis and ovary. Ovary almost completely inhibited in development, showing only occasional primary follicles (A) and isolated groups of sex cords (B). Normal-appearing seminiferous tubules in testicular portion of graft are evident in lower half of photograph. $\times 91$.

4 Graft of 15-day embryonie testis and ovary. Note tubular structures in ovarian portion of transplant as compared with seminiferous tubules of testis (lower third of photograph). $\times 91$.

5 Enlarged view of seminiferous tubule from tissue shown in figure $4 . \times 392$.

6 Enlarged view of ovarian tubules from tissue shown in figure $4 . \times 392$. 

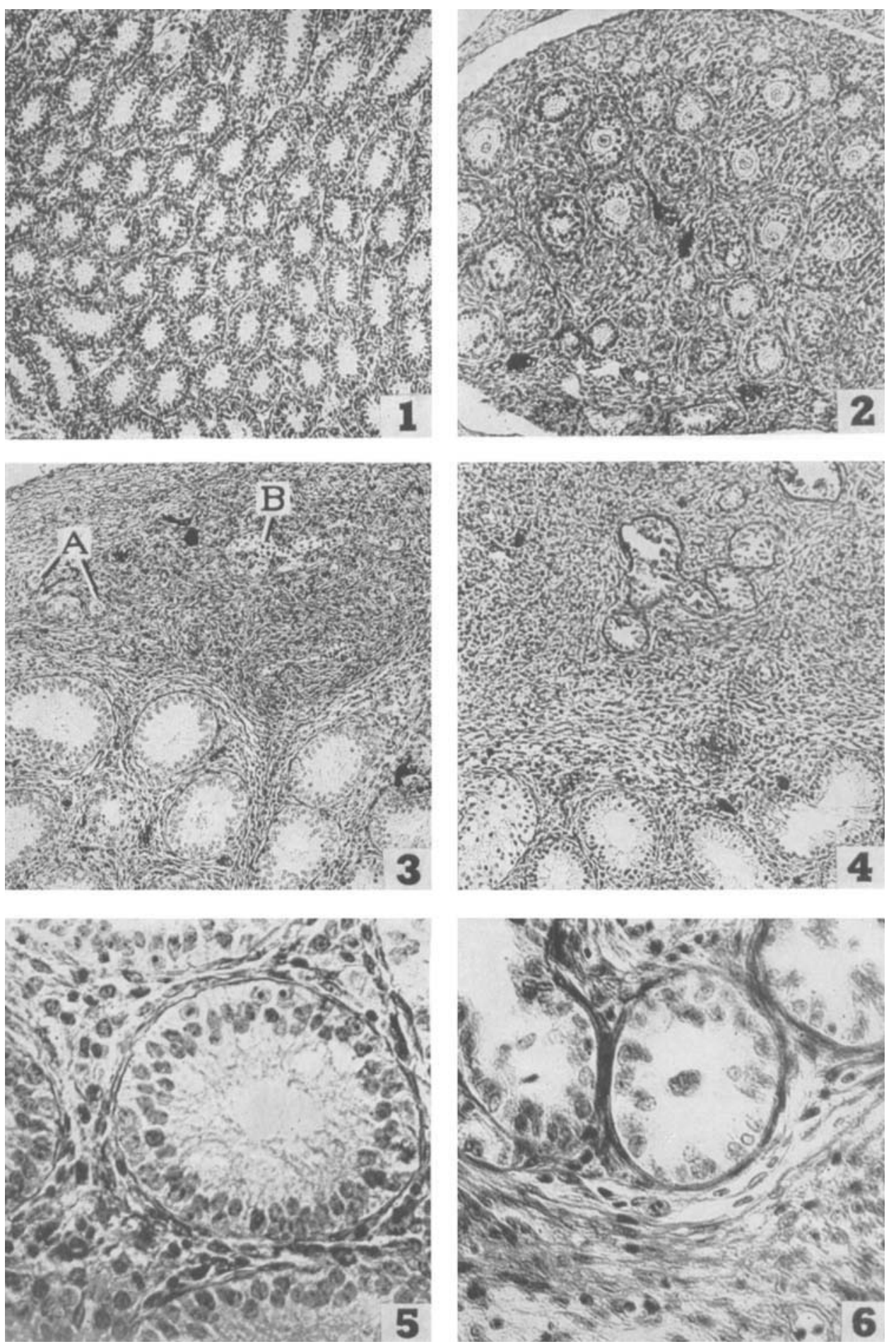


\section{PLATE 2}

EXPLANATION OF FIGURES

7 Ovarian portion from graft of 15-day embryonic testis and ovary. Note two follicles joined by a long tubule. Serial sections on each side of the one reproduced, show that the lumen of the tubule is continuous with the antra of both follicles so that the structure is essentially a greatly distorted follicle containing two oocytes. $\times 91$.

8 Graft of 15-day embryonie testis and ovary showing large ovarian tubule containing several well developed oocytes. The broken line A-B marks boundary between ovary above and testis below. Note morphological similarity between ovarian tubules and seminiferous tubules of testis. $\times 91$.

9 Enlarged view of oocytes shown in figure $8 . \times 392$.

10 Graft of 15-day embryonic ovary and adrenal gland showing good deveiopment of both organs. $\times 31$.

11 Graft of 15-day embryonie ovary grown alone in kidney of castrate adult host. Compare follicular development with that in normal ovary of same age (fig. 2). $\times 91$.

12 Graft of 15-day embryonic ovary grown alone in kidney of normal (noncastrate) adult male host. Compare follicular development with that in normal ovary of same age (fig. 2). $\times 91$. 

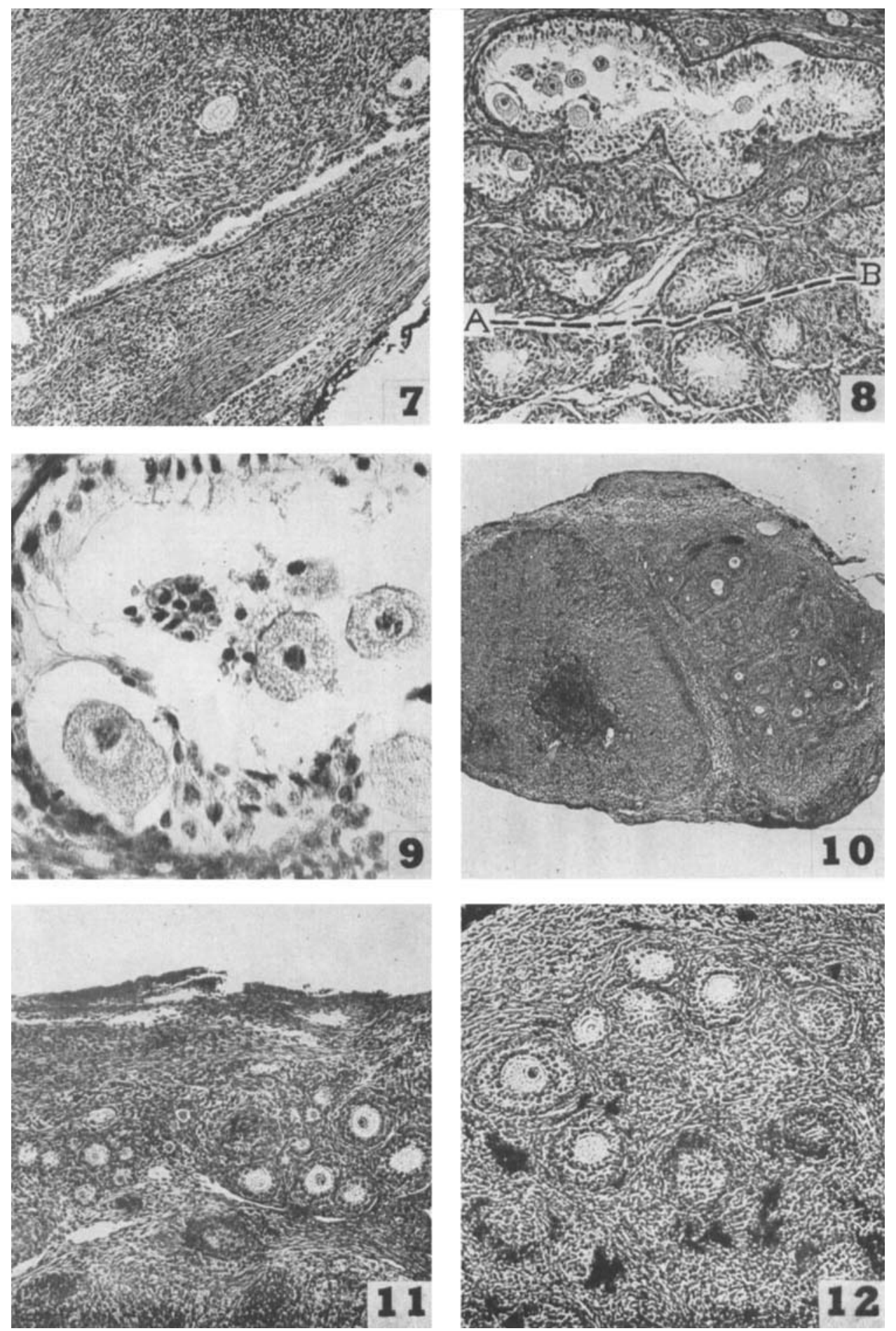